\title{
Research
}

\section{A Facilitative Role for Corticosterone in the Acquisition of a Spatial Task Under Moderate Stress}

\author{
Irit Akirav, ${ }^{1}$ Maya Kozenicky, ${ }^{1}$ Dadi Tal, ${ }^{1}$ Carmen Sandi, ${ }^{2}$ Cesar Venero, ${ }^{2}$ \\ and Gal Richter-Levin ${ }^{1,3}$ \\ ${ }^{1}$ Department of Psychology and the Brain and Behavior Research Center, University of Haifa, Haifa 31905, Israel; ${ }^{2}$ Psychobiology \\ Department, Universidad Nacional de Educacion a Distancia Ciudad s/n Madrid (UNED), Madrid 28040, Spain
}

\begin{abstract}
Emotionally charged experiences alter memory storage via the activation of hormonal systems. Previously, we have shown that compared with rats trained for a massed spatial learning task in the water maze in warm water $\left(25^{\circ} \mathrm{C}\right)$, animals that were trained in cold water $\left(19^{\circ} \mathrm{C}\right)$ performed better and showed higher levels of the stress hormone corticosterone. Here, we examined whether manipulating the levels of corticosterone can determine the strength of spatial information acquisition and retention. Rats were injected with metyrapone $(25,50$, and $75 \mathrm{mg} / \mathrm{kg}$, i.p.) or with corticosterone (10 and $25 \mathrm{mg} / \mathrm{kg}$, i.p.) and trained in a massed spatial task in either cold $\left(19^{\circ} \mathrm{C}\right)$ or warm $\left(25^{\circ} \mathrm{C}\right)$ water. We found that whereas animals injected with vehicle performed well in the spatial task in cold water (moderate stress), rats injected with the intermediate metyrapone dose showed impairment in performance. Moreover, whereas animals injected with vehicle on average did not perform well in warm water (mild stress), rats injected with the lower corticosterone dose showed improvement in performance in warm water. These two mirror experiments of corticosterone blockade and enhancement strongly suggest that corticosterone is instrumental in the acquisition and retention of the spatial learning task.
\end{abstract}

Emotional and stressful experiences, via the activation of specific hormonal and brain systems, alter brain function and regulate memory storage. The response to stress involves the activation of glucocorticoids (corticosterone in rats). These notably bind to mineralcorticoid and glucocorticoid receptors (MRs and GRs) in the hippocampus (Reul and de Kloet 1985; McEwen et al. 1986; McEwen and Sapolsky 1995), which is involved in the processing of spatial and contextual information (Morris et al. 1982; Meck et al. 1984; Moser et al. 1993; Alvarado and Rudy 1995). The effects of stress and/or glucocorticoids on hippocampus-dependent learning follow an inverted U-shaped dose-response relationship; extreme low and high levels may impair consolidation, whereas moderate activation seems to be a prerequisite for the long-term storage of information (Flood et al. 1978; Diamond et al. 1992, 1999; Oitzl et al. 1994; Sandi and Rose 1994a,b; Vaher et al. 1994; Yau et al. 1995; Conrad et al. 1997; Pugh et al. 1997; Liu et al. 1999). For example, a high dose of corticosterone or stress prior to training or testing resulted in impaired spatial performance and memory (Diamond et al. 1996; de Quervain et al. 1998; Conrad et al. 1999). Similarly, the removal of endogenous corticosterone (by adrenalectomy or GR antagonist) impaired performance in a spatial task and fear conditioning (Oitzl and de Kloet 1992; Vaher et al. 1994; Pugh et al. 1997).

However, a different picture emerges when one evaluates the effects of the stress reaction elicited during the training situation. We have shown (Sandi et al. 1997) that rats trained in cold water $\left(19^{\circ} \mathrm{C}\right)$ for a spaced spatial task in the water maze $(3 \mathrm{~d}$ of training) displayed a quicker rate of acquisition and better longterm retention than rats trained in warm water $\left(25^{\circ} \mathrm{C}\right)$. Importantly, posttraining corticosterone levels at the end of the training day were significantly higher in rats in the $19^{\circ} \mathrm{C}$ group than in the $25^{\circ} \mathrm{C}$ group, and rats trained at $25^{\circ} \mathrm{C}$, but not at $19^{\circ} \mathrm{C}$,

${ }^{3}$ Corresponding author.

E-MAIL gal.r-I@psy.haifa.ac.il; FAX 972-4-8240966.

Article and publication are at http://www.learnmem.org/cgi/doi/10.1101/ Im.61704. showed better performance following a corticosterone injection immediately after each training session. In a more recent study (Akirav et al. 2001), we found similar results using a massed spatial task in the water maze ( $1 \mathrm{~h}$ of training in $1 \mathrm{~d})$. The massed protocol was found to generate long-term spatial memory (Akirav et al. 2001); it may be advantageous for spaced training, as it allows a more accurate definition of the learning process. Animals trained in the massed spatial task at $19^{\circ} \mathrm{C}$ showed good performance, whereas animals trained at $25^{\circ} \mathrm{C}$ were split into two groups, one that performed as well as the cold-water trained animals and another that performed poorly (i.e., showed longer latency to reach the hidden platform in the water maze). Moreover, animals trained at $19^{\circ} \mathrm{C}$ showed higher levels of corticosterone immediately following the training than animals trained at $25^{\circ} \mathrm{C}$.

Here, we aimed to examine whether manipulating corticosterone levels can determine the strength of spatial information acquisition. Specifically, (1) will raising corticosterone levels in rats trained in a mild stress situation (warm water) improve acquisition in the massed spatial task to the level seen in rats trained in the moderate stress situation (cold water), and (2) will suppressing corticosterone levels in rats trained at the moderate stress situation (cold water) deteriorate acquisition in the massed spatial task to the level seen in rats trained in the mild stress situation (warm water)?

\section{RESULTS}

\section{Metyrapone Decreases and Corticosterone Increases} Circulating Corticosterone Levels

Circulating corticosterone (CORT) levels were measured following metyrapone or corticosterone supplementation to examine whether metyrapone and corticosterone, respectively, reduce and increase corticosterone circulating levels.

Animals were injected with vehicle, or $50 \mathrm{mg} / \mathrm{kg}$ metyrapone, or $10 \mathrm{mg} / \mathrm{kg}$ corticosterone, and after $2 \mathrm{~h}$, swam in cold 
water (metyrapone group) or warm water (corticosterone group) for one block (two trials; no escape platform in the maze). The rationale for the test in cold or warm water was that without drugs, cold water was found to be associated with higher levels of corticosterone than warm water (Sandi et al. 1997; Akirav et al. 2001). The metyrapone was aimed to produce in cold water, warm water-like levels of corticosterone, whereas corticosterone was applied to produce in warm water, cold water-like levels of corticosterone. Corticosterone levels were measured $20 \mathrm{~min}$ following the end of the block. ANOVA revealed a significant difference in corticosterone levels between the groups $\left(\mathrm{F}_{(3,24)}=31.88, P<0.0001 ;\right.$ Fig. 1). Post-hoc comparisons for the difference in corticosterone levels (data represent the means \pm SEM expressed as $\mathrm{ng} / \mathrm{ml}$ ) showed a significant difference between the Vehicle Cold Water $(n=7)$ and $50 \mathrm{mg} / \mathrm{kg}$ metyrapone cold water (50Met Cold Water, $n=7)$ group $(P<0.001)$, and a significant difference between the Vehicle Warm Water $(n=7)$ and $10 \mathrm{mg} / \mathrm{kg}$ corticosterone warm water (10CORT Warm Water, $n=7)$ group $(P<0.05)$. Thus, $50 \mathrm{mg} / \mathrm{kg}$ metyrapone reduced and $10 \mathrm{mg} / \mathrm{kg}$ CORT increased circulating corticosterone levels. Additionally, there was a significant difference between the Vehicle Warm Water and Vehicle Cold Water group $(P<0.01)$, which further supported the notion that exposure to cold water would result in higher corticosterone levels than exposure to warm water.

\section{Massed Training at Different Water Temperatures Differentially Affects the Performance of Rats in the Spatial Task}

Animals injected with vehicle were trained in the massed schedule in either cold water $\left(19^{\circ} \mathrm{C}, n=13\right)$ or warm water $\left(25^{\circ} \mathrm{C}\right.$, $n=25)$. All of the animals trained in cold water performed the

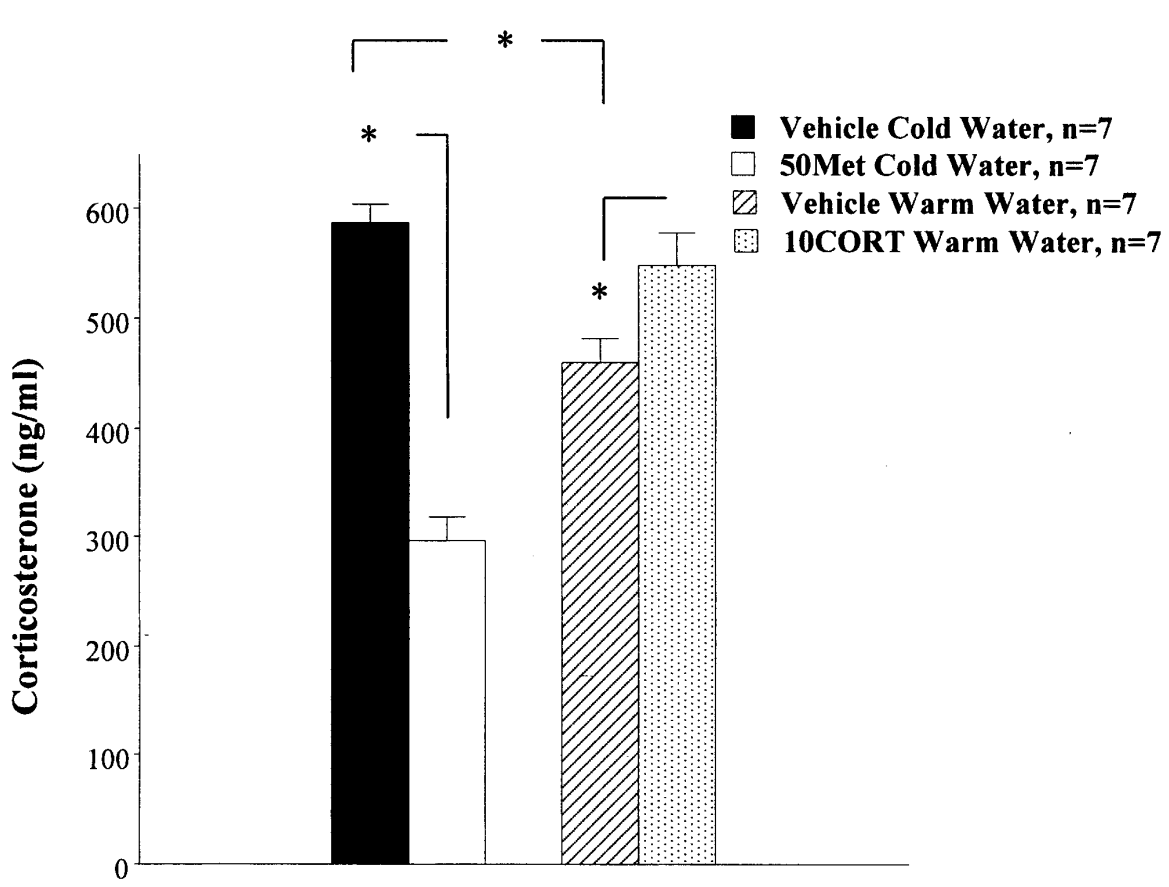

Figure 1 Myterapone decreases and corticosterone increases circulating corticosterone levels. A significant difference in corticosterone levels (data represent the means \pm SEM expressed as nano$\mathrm{gram} / \mathrm{milliliter}$ ) was found between the vehicle cold water and the $50 \mathrm{mg} / \mathrm{kg}$ metyrapone cold water groups (50Met Cold Water; ${ }^{*}, P<0.001$ ), and a significant difference between the vehicle warm water and the $10 \mathrm{mg} / \mathrm{kg}$ corticosterone warm water groups (10CORT Warm Water, $*, P<0.05$ ). Thus, 50 $\mathrm{mg} / \mathrm{kg}$ metyrapone reduced and $10 \mathrm{mg} / \mathrm{kg}$ CORT increased circulating corticosterone levels. Additionally, there was a significant difference between the vehicle warm water and vehicle cold water group $\left({ }^{*}, P<0.01\right)$, which further supports the notion that training in cold water is more stressful (i.e., results in higher corticosterone levels) than training in warm water. task well [low latency $(<20 \mathrm{sec})$ to reach the platform on the last four trials], whereas there was a differential performance in the warm water-trained rats; about half of the animals trained in warm water performed the task well (they reached the platform in $<20 \mathrm{sec}$ ), whereas the other half showed higher latencies in reaching the platform. This confirms our previous findings (Akirav et al. 2001).

To determine whether corticosterone may differentially affect learning depending on the degree of performance exhibited, the Warm Water group was divided into two groups, classified as Warm Water $(+)(n=11)$ or Warm Water $(-)(n=14)$, depending on their latency in reaching the platform [20 sec or less was assified as Warm Water (+)].

An overall mixed ANOVA [treatment $\times$ trials $(8 \times 8)$ ] showed a significant difference between groups in mean escape latency $\left[\mathrm{F}_{(7,75)}=5.918, P<0.001\right]$. Post-hoc comparison for the difference in mean escape latency revealed a signifigroups (before the split into two groups) on the last three blocks (trials 11-16; $P<0.05$; data not shown) and a significant difference between the Warm Water $(-)$ group and both the Cold Water $(P<0.001)$ and the Warm Water $(+)(P<0.001)$ groups (Fig. 2A; after the split into two groups) with no significant difference between the Cold Water and the Warm Water (+) groups.

Table 1 shows the swim speed ( \pm SEM) of naive animals that were injected with either vehicle or the corticosteroidrelated drugs $2 \mathrm{~h}$ before exposure to a 60-sec swim trial (no platform) in cold or warm water. The aim of this trial was to examine possible differences in motor performance that may have been caused by the different drugs or the water temperatures. There was no significant difference between the Cold Water $(n=8)$ and the Warm Water $(n=7)$ groups in their swim speed $\left(t_{(13)}<1\right.$, NS), so the effects seen cannot be attributed to gross disturbances in general activity.

In the quadrant test following the training, the Cold Water group showed a significant bias to swim the longest distance within the quadrant in which the platform had been located previously (Q2-target, $t$-test for difference from chance $(25 \%): t_{(12)}=6.3326, P<0.0001$; Fig. 2B). However, both the Warm Water $(+)$ and the Warm Water $(-)$ groups showed no such bias [Warm Water $(+)$ : $t_{(10)}=1.4043$, NS; Warm Water $(-)$ : $\left.t_{(13)}=1.0911, \mathrm{NS}\right)$.

Table 2 shows the swim speed (means \pm SEM) of the groups during the quadrant test; there was no significant difference between the groups in their swim speed $\left(\mathrm{F}_{(2,35)}=1.202\right.$, NS), so it cannot be claimed that the animals in the Cold Water group swam a shorter distance within the quadrant in which the platform had been located previously, due to the effect of the water temperature on general activity.

\section{Metyrapone Dose-Dependently Affects the Performance of Animals Trained in Cold Water}

Animals were injected with vehicle (Cold Water), or $25 \mathrm{mg} / \mathrm{kg}$ metyrapone 
A

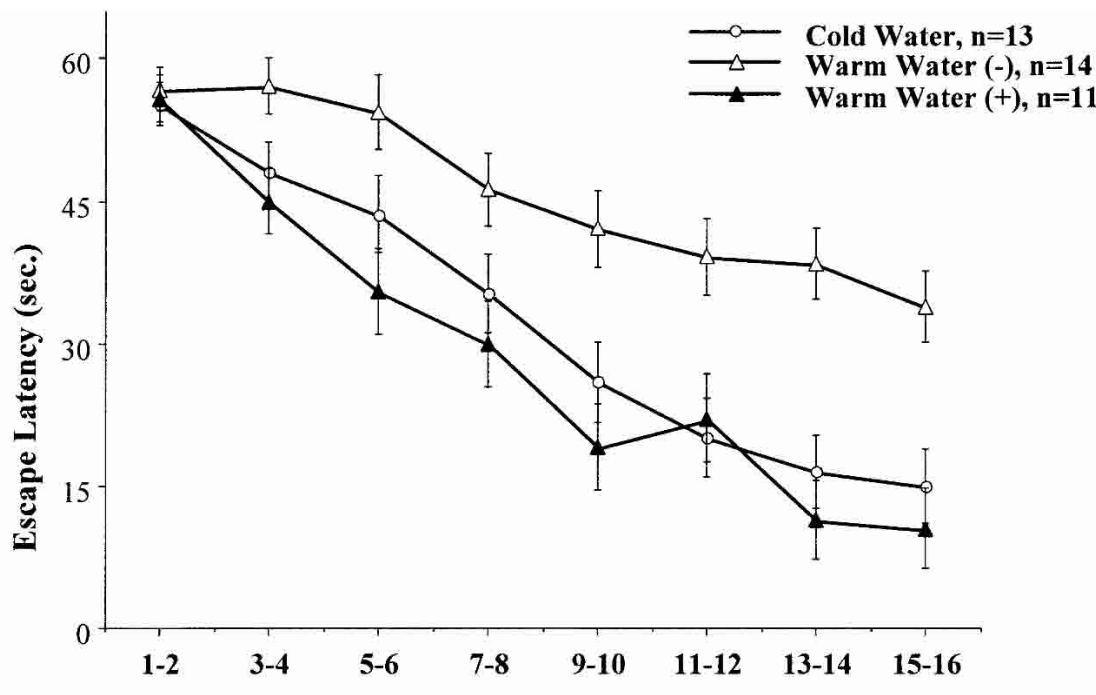

B

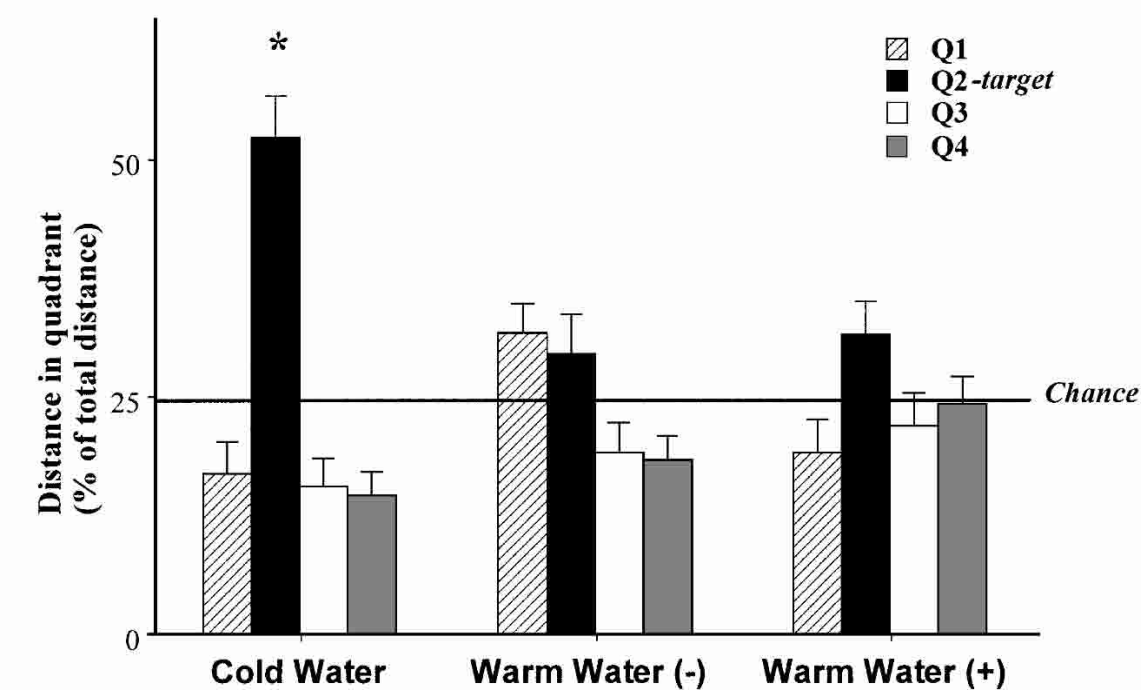

Figure 2 Massed training at different water temperatures differentially affects the performance of rats in the spatial task. (A) All animals trained at $19^{\circ} \mathrm{C}$ (Cold Water) have acquired the task. Animals trained at $25^{\circ} \mathrm{C}$ were divided into two groups, animals that reached the platform four consecutive times in $20 \mathrm{sec}$ or less [Warm Water $(+)$ ] and animals that showed higher latencies in reaching the platform [Warm Water $(-)]$. A significant difference in performance (measured as escape latency) was found between the Warm Water $(-)$ group and both the Cold Water $(P<0.001)$ and the Warm Water $(+)(P<0.001)$ groups, with no significant difference between the Cold Water and the Warm Water $(+)$ groups. $(B)$ A quadrant analysis test was conducted $1 \mathrm{~h}$ following the last behavioral trial. Rats in the Cold Water group showed a significant bias to swim the longest distance within the quadrant in which the platform had been located previously (Q2; * significant difference from chance level (25\%): $P<0.0001)$. In contrast, the Warm Water $(+)$ and the Warm Water $(-)$ groups showed no such bias. This may suggest a primary difference in the quality of the spatial memory between the animals trained in cold water and the good performers of the warm water group, which although they performed well in training $(A)$, failed to perform well in the test $(B)$.

(25Met Cold Water, $n=9$ ), or $50 \mathrm{mg} / \mathrm{kg}$ metyrapone (50Met Cold Water, $n=9$ ), or $75 \mathrm{mg} / \mathrm{kg}$ metyrapone (75Met Cold Water, $n=9$ ), and were trained for a spatial task (Fig. 3A).

Post-hoc comparison for the difference in the mean escape latency revealed a significant difference between the Cold Water group and both the 50Met Cold Water $(P<0.05)$ and the $75 \mathrm{Met}$ Cold Water $(P<0.05)$ groups, but with no significant difference between the Cold Water and the 25Met Cold Water groups. In addition, the 25Met Cold Water group was significantly different from both the 50Met Cold Water $(P<0.05)$ and the 75Met Cold Water $(P<0.05)$ groups, but with no significant difference between the 50Met Cold Water and the $75 \mathrm{Met}$ Cold Water groups.

On the 60-sec swim trial (Table 1), there was a significant difference between the groups in their swim speed $\left(\mathrm{F}_{(3,23)}=4.015, P=0.02\right)$. Post-hoc comparisons showed a significant difference between the 50Met Cold Water group $(n=9)$ and both the Cold Water $(n=8$; $P<0.01)$ and the $25 \mathrm{Met}$ Cold Water $(n=5 ; P<0.05)$ groups, with no significant difference between the 50Met Cold Water and the 75Met Cold Water group.

Note that although the 50Met Cold Water group showed faster swimming speed, they performed poorly in the test.

In the quadrant test, the Cold Water group showed a significant bias to swim the longest distance within the quadrant in which the platform had been located previously (Fig. 3B; as in Fig. 2B). However, all of the other groups showed no such bias $(\mathrm{Q} 2, t$-test for difference from chance (25\%): 25Met Cold Water: $t_{(8)}=1.336$, NS; 50Met Cold Water: $t_{(8)}<1$, NS; $75 \mathrm{Met}$ Cold Water: $t_{(8)}<1$, NS).

In addition, there was no significant difference between the groups in their swim speed during the test $\left(\mathrm{F}_{(3,36)}<1, \mathrm{NS}\right)$, indicating that the performance in the test was not affected by any gross disturbances in motor activity.

\section{Corticosterone Dose Dependently} Affects the Performance of Animals Trained in Warm Water

Animals injected with vehicle and trained in warm water were divided into two groups and classified as Warm Water $(+)$ and Warm Water $(-)$ on the basis of their performance. Two additional groups were trained in warm water following CORT injection of either $10 \mathrm{mg} /$ $\mathrm{kg}$ corticosterone (10CORT Warm Water, $n=9$ ) or $25 \mathrm{mg} / \mathrm{kg}$ corticosterone (25CORT Warm Water, $n=9$ ) (Fig. 4A). Post-hoc comparison showed a significant difference between the Warm Water $(+)$ group and both the Warm Water $(-)(P<0.001)$ and the 25CORT Warm Water $(P<0.01)$ groups, but not between the Warm Water (+) group and the 10CORT Warm Water group. In addition, there was a significant difference between the 10CORT Warm Water group and both the Warm Water $(-)$ $(P<0.001)$ and the 25 CORT Warm Water $(P<0.001)$ groups, but not between the Warm Water $(-)$ group and the 25CORT Warm Water group.

On the 60-sec swim trial (Table 1), there was no significant difference $\left(\mathrm{F}_{(2,15)}=1.284\right.$, NS) between the Warm Water group 
Table 1. Swim Speed During the $60-$ Sec Trial

\begin{tabular}{lc}
\hline Groups & $\begin{array}{c}\text { Swim Speed } \\
\text { (means } \pm \text { SEM) }\end{array}$ \\
\hline Cold Water, $n=8$ & $20.74 \pm 0.92$ \\
Warm Water, $n=7$ & $20.20 \pm 0.98$ \\
25Met Cold Water, $n=5$ & $20.56 \pm 1.16$ \\
50Met Cold Water, $n=9$ & $24.75 \pm 0.87^{*}$ \\
75Met Cold Water, $n=5$ & $22.49 \pm 1.16$ \\
10CORT Warm Water, $n=5$ & $20.56 \pm 1.16$ \\
25CORT Warm Water, $n=6$ & $22.37 \pm 1.16$ \\
\hline
\end{tabular}

The means \pm SEM of swim speeds $(\mathrm{cm} / \mathrm{sec})$ of naive animals that were injected with either vehicle or the corticosteroid-related drugs 2 $\mathrm{h}$ before exposure to a 60 -sec swim trial (no platform) in cold or warm water [ ${ }^{*}$ indicates a significant difference between the 50Met Cold Water group and the Cold Water $(P<0.01)$, Warm Water $(P<0.001)$, 25Met Cold Water $(P<0.01)$, and 25CORT $(P<0.05)$ groups].

$(n=7)$, the 10CORT Warm Water group ( $n=5)$, and the 25CORT Warm Water group $(n=6)$, indicating that the effects seen were not due to any gross changes in motor activity.

In the quadrant test, the 10CORT Warm Water group showed a significant bias to swim the longest distance within the quadrant in which the platform had been located previously (Fig. $4 \mathrm{~B}$; Q2, $t$-test for difference from chance $(25 \%): t_{(8)}=2.9437$, $P<0.05)$. In contrast, the 25CORT Warm Water group showed no such bias (Q2, $t$-test for difference from chance $(25 \%): t_{(8)}<1$, NS).

In addition, there was no significant difference between the groups in their swim speed $\left(\mathrm{F}_{(3,39)}=1.52\right.$, NS; Table 2$)$, implying that the performance in the test was not affected by any gross disturbances in motor activity.

\section{Animals Treated With Both Metyrapone and Corticosterone Show Good Performance in Cold Water}

Animals were injected with vehicle (Vehicle, $n=8$ ) or with both $50 \mathrm{mg} / \mathrm{kg}$ metyrapone and $10 \mathrm{mg} / \mathrm{kg}$ CORT (Met and CORT, $n=8$ ) and were trained for a spatial task in cold water (Fig. 5A). Both groups performed the task well and showed no significant difference in the mean escape latency.

In the quadrant test, both groups showed a significant bias to swim the longest distance within the quadrant in which the platform had been located previously (Fig. 5B; Q2, $t$-test for difference from chance (25\%): Vehicle: $t_{(7)}=5.7, P<0.001$; Met and CORT: $\left.t_{(7)}=3.49, P<0.01\right)$. This may suggest that the effects of metyrapone (Fig. 3) could be mainly due to its effect on the glucocorticoid system.

\section{DISCUSSION}

This work supports the notion that corticosterone levels may determine the different degree of the acquisition of the learned response; animals that performed well in the massed spatial task in cold water (moderate stress) deteriorated following the suppression of corticosterone levels, whereas animals trained in warm water (mild stress), and on average did not perform as well as the cold water-trained animals, improved following the rise in corticosterone levels.

Training at Different Water Temperatures Differentially Affects Acquisition and Retrieval of the Spatial Task

Training rats at different water temperatures significantly affected both their acquisition and retention of a spatial learning task. All animals trained in cold water showed good acquisition of the task and all performed well in the test $1 \mathrm{~h}$ following the training. However, animals that were trained in warm water showed a different pattern; about half of them performed the task as well as the cold water-trained animals, whereas the other half performed poorly. It was demonstrated previously that corticosterone levels were found to be higher in animals trained in cold water than animals trained in warm water, when examined 5 min following the end of training (Akirav et al. 2001; see also Sandi et al. 1997). Although our previous results indicate a small difference in corticosterone levels between the cold water and the warm water animals trained in the massed task (Akirav et al. 2001), note that even subtle differences in MR and GR occupation may influence the outcome of activated neural circuits, and that the effects of corticosterone on performance can switch from an improvement to impairment, depending on the context and duration of GR activation (Oitzl et al. 1998).

Interestingly, although the animals that performed well at the warm temperature were no different from cold water-trained animals in the acquisition of the task and showed no disturbances in their motor activity (i.e., showed similar swim speed), they performed poorly in the quadrant test $1 \mathrm{~h}$ later. This may indicate that despite the similar acquisition pattern of these two groups, consolidation mechanisms were more efficient in the cold water group. It is thus possible that corticosterone release elicited by the water temperature may have acted differently on consolidation mechanisms during and/or following the training, and that this led to differential performance in the test.

It has been shown that rats trained at $19^{\circ} \mathrm{C}$ showed better performance in the retention test than rats trained at $25^{\circ} \mathrm{C}$ (Sandi et al. 1997), whereas rats trained at $12^{\circ} \mathrm{C}$ showed impaired performance and significantly higher corticosterone levels than rats trained at 25 or $19^{\circ} \mathrm{C}$ (Selden et al. 1990; Sandi et al. 1997). It has been suggested that this difference in performance between the 19 and $25^{\circ} \mathrm{C}$-trained animals results from corticosterone involvement in consolidation processes, whereas the impaired performance of the $12^{\circ} \mathrm{C}$-trained rats results from the involvement of other stress-activated systems (not corticosteroids; Selden et al. 1990; Sandi et al. 1997).

\section{Manipulating Corticosterone Levels Determines the Acquisition and Retention Performance}

When animals trained in cold water were injected with metyrapone, which blocks the stress-induced increase in plasma corticosterone levels, their performance deteriorated in a dosedependent manner; the higher the metyrapone dose, the worse the performance. Compared with the vehicle- and the low dose metyrapone-injected groups, animals injected with the intermediate dose of metyrapone showed higher swim speed. However, this increase in swim speed did not result in shorter escape latencies. On the contrary, these animals were significantly slower

Table 2. Swim Speed During the Quadrant Test

\begin{tabular}{lc}
\hline Groups & $\begin{array}{c}\text { Swim Speed } \\
\text { (means } \pm \text { SEM) }\end{array}$ \\
\hline Cold Water, $n=13$ & $26.76 \pm 1.86$ \\
Warm Water $(-), n=14$ & $21.58 \pm 1.79$ \\
Warm Water $(+), n=11)$ & $23.81 \pm 2.02$ \\
25Met Cold Water, $n=9$ & $25.01 \pm 2.23$ \\
50Met Cold Water, $n=9$ & $26.17 \pm 2.23$ \\
75Met Cold Water, $n=9$ & $26.92 \pm 2.23$ \\
10CORT Warm Water, $n=9$ & $25.96 \pm 2.23$ \\
25CORT Warm Water, $n=9$ & $23.11 \pm 2.23$ \\
\hline
\end{tabular}

The means \pm SEM of swim speeds $(\mathrm{cm} / \mathrm{sec})$ of the different groups in the quadrant test. No significant treatment effect was found. 
A

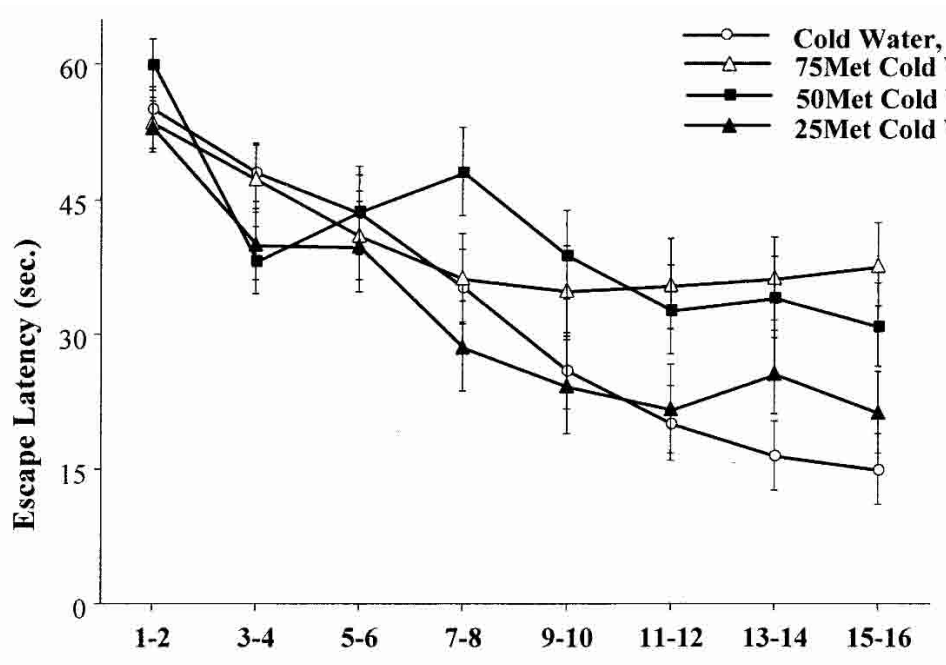

Trials

B

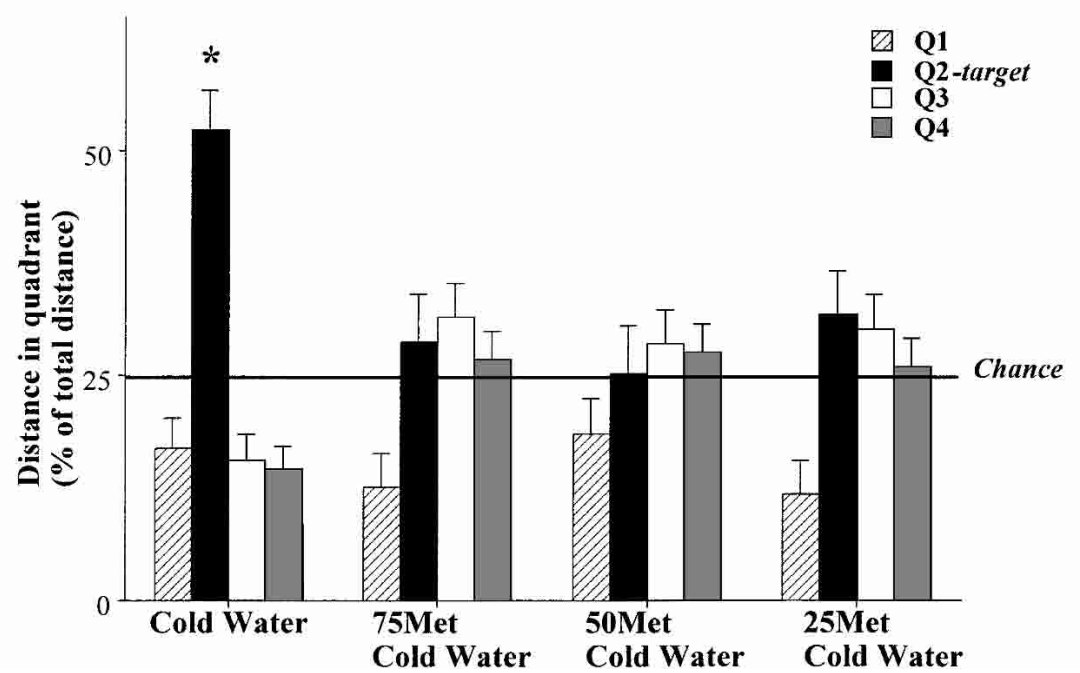

Figure 3 Metyrapone dose dependently affects the performance of animals trained in a massed schedule in cold water. ( $A$ ) A significant difference in performance (measured as escape latency) was found between the Cold Water group and both the 50Met Cold Water $(P<0.05)$ and the 75Met Cold Water $(P<0.05)$ groups, with no significant difference between the Cold Water and the 25Met Cold Water group. In addition, the $25 \mathrm{Met}$ Cold Water group was significantly different from both the $50 \mathrm{Met}$ Cold Water $(P<0.05)$ and the 75Met Cold Water $(P<0.05)$ groups, with no significant difference between the $50 \mathrm{Met}$ Cold Water and the $75 \mathrm{Met}$ Cold Water groups. This suggests a concentrationdependent effect of metyrapone on the performance in the massed spatial task, i.e., the higher the metyrapone dose, the worse the performance. $(B)$ In the quadrant test, the Cold Water group showed a significant bias to swim the longest distance within the quadrant in which the platform had been located previously $\left(\mathrm{Q} 2 ;{ }^{*}, P<0.0001\right)$. However, all the other groups showed no such bias.

very high levels of corticosterone impair learning (Conrad et al. 1999; Diamond et al. 1999).

Others have shown that a lower dose of corticosterone $(3 \mathrm{mg} / \mathrm{kg}) \mathrm{im}$ paired retention in a spatial task when injected $30 \mathrm{~min}$ prior to the test (de Quervain et al. 1998); however, here the corticosterone injection was applied prior to the acquisition training and not prior to the test, so the differences may have resulted from distinct effects of circulating corticosterone levels on different stages of the learning.

There was no difference in the swim speed between the corticosteroneinjected groups and the vehicle group. Thus, the bad performance of the high corticosterone group cannot be attributed to gross disturbances in activity. The impaired performance in the high corticosterone dose may be due to interference that is mediated by stressactivated systems other than corticosteroids, for example, the coeruleo-cortical noradrenergic system (Selden et al. 1990). Water-maze learning induces a high level of endogenous adrenergic hormone release (Mabry et al. 1995), and it has been shown that in animals trained at $25^{\circ} \mathrm{C}$, and separated into "good learners" (lower latency in reaching the platform) and "poor learners", systemic administration of the $\beta$-adrenergic antagonist propranolol caused retrograde amnesia in the "good learners" but not in the "poor learners" (Cahill et al. 2000). This substantiates the possible involvement of post-learning adrenergic activation in modulating memory consolidation processes after emotionally stressful events (Cahill et al. 2000).

Nevertheless, we found that animals trained in cold water and injected with both a low dose of metyrapone and CORT performed well in the training session and the retention probe. This may suggest that the effects of metyrapone seen here (impairing the performance of animals trained in cold water) are mainly due to its effects on the glucocorticoids system and not to alterations in other hormonal systems.

Taken together, the results of the

than the control and the low-dose metyrapone group in reaching the escape platform. Furthermore, as animals injected with the high dose of metyrapone showed impaired acquisition and retention, but not increased swim speed, the poor performance seen in the intermediate group cannot be explained on the basis of disturbances resulting from enhanced activity.

Animals injected with a low dose of corticosterone $(10 \mathrm{mg} /$ $\mathrm{kg}$ ) and trained in warm water showed better performance in both the acquisition and the retrieval of the spatial task than animals injected with the higher dose of corticosterone. This confirms previous reports indicating that moderate levels of corticosterone may facilitate learning (Sandi et al. 1997), whereas two mirror experiments, that is, that enhancing corticosterone levels may enhance performance, whereas blocking its release impairs it, strongly suggest that corticosterone levels are instrumental in the acquisition and retention of the spatial learning task.

\section{The Inverted U-Shaped Function}

The effectiveness of performance over a continuum of stress and/ or corticosterone levels generally follows an inverted U-shaped function; the lower performance associated with very low levels of stress is usually explained by the low motivation that accom-

\section{Learning \& Memory} www.learnmem.org 
A

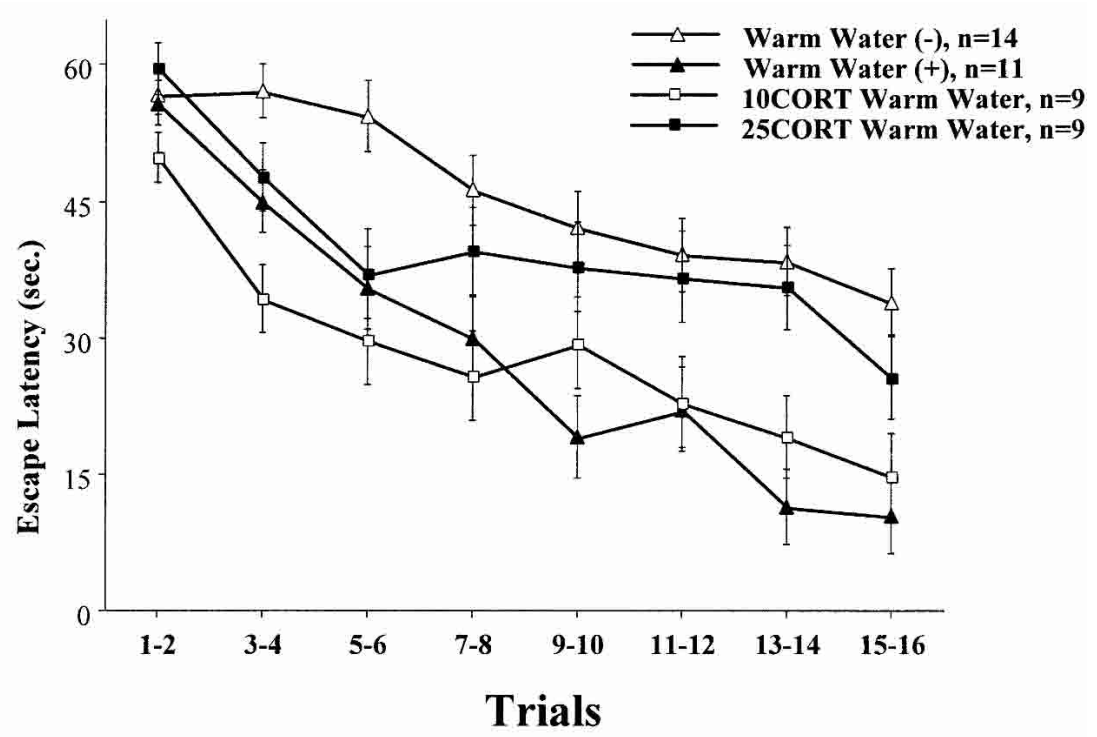

B

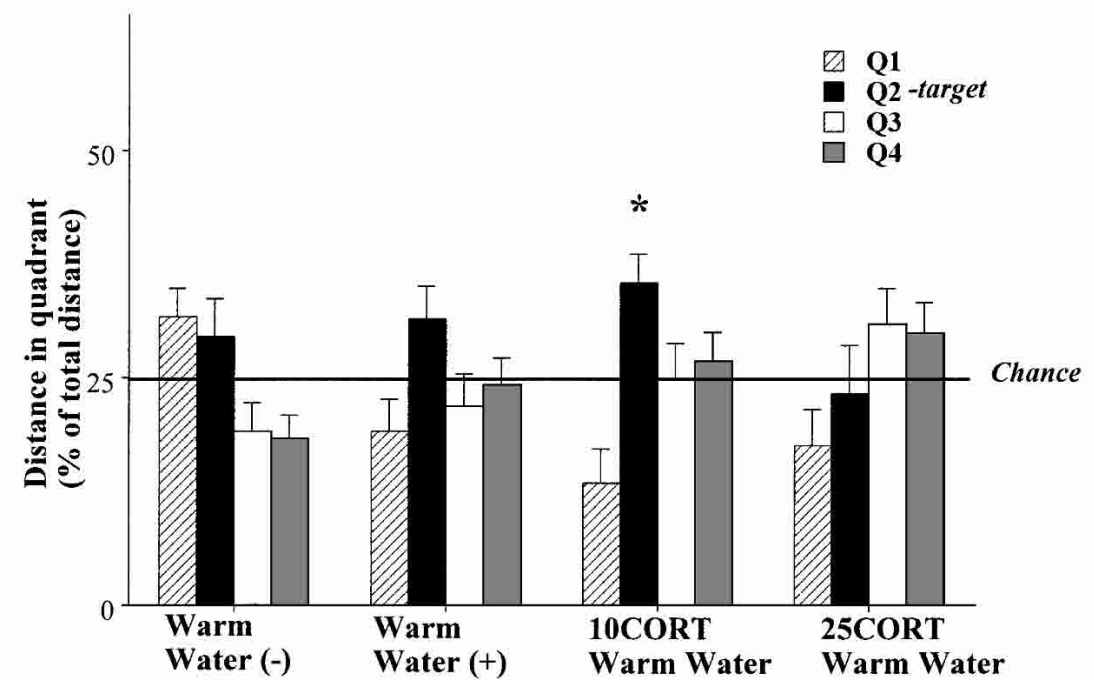

Figure 4 Corticosterone dose dependently affects the performance of animals trained in warm water. $(A)$ A significant difference in performance (measured as escape latency) was found between the Warm Water $(+)$ group and both the Warm Water $(-)(P<0.001)$, and the 25CORT Warm Water $(P<0.01)$ groups, but not between the Warm Water $(+)$ group and the 10CORT Warm Water group. In addition, there was a significant difference between the 10CORT Warm Water group and both the Warm Water $(-)(P<0.001)$ and the 25CORT Warm Water $(P<0.001)$ groups, but not between the Warm Water (-) group and the 25CORT Warm Water group. This suggests a concentrationdependent facilitative effect of corticosterone on the performance in the spatial learning task. $(B)$ In the quadrant test, the 10CORT Warm Water group showed a significant bias to swim the longest distance within the quadrant in which the platform had been located previously $\left(\mathrm{Q} 2 ;{ }^{*}, P<0.05\right)$. In contrast, the 25CORT Warm Water group showed no such bias.

panies the low stress and the ease with which the subject is therefore diverted from the problem by extraneous factors (Vroom 1964; Anderson 1976). At intermediate stress levels, the level of motivation to solve the problem reaches the optimum zone. Here, the stress broadens the attention span so that the subject is more amenable to relevant information (e.g., spatial cues in the environment) that may actually aid its performance (Easterbrook 1959; Selden et al. 1990). Under high levels of stress, on the other hand, motivation to solve the task may be so high that the subject's perception narrows to only very obvious cues, and it ignores relevant information. However, it may be that under such conditions, subjects will perform well on an easy task and will fail to acquire more demanding tasks (Selden et al. 1990). Under extreme conditions, however, the high anxiety associated with the high stress may lead to physiological involuntary autonomic responses that interfere with performance (Vroom 1964).

Training in the water maze is stressful, especially under a 1-d massed schedule protocol (Akirav et al. 2001). In the two groups that showed good performance both in the training and the test (the Cold Water and $10 \mathrm{mg} / \mathrm{kg}$ CORT Warm Water groups), corticosterone levels were equivalent to those in a fairly stressful situation (Sandi et al. 1997; Akirav et al. 2001). In addition, the warm water group that did not perform well showed substantially increased corticosterone levels compared with naive animals (Akirav et al. 2001). These results seem to suggest that under the conditions above, there is a rightward shift in the corticosterone inverted $U$ curve, such that relatively high corticosterone levels are within the optimum zone. Only at very high levels, as in the animals injected with a high dose of corticosterone, is performance impaired.

A possible explanation for a rightward shift may be the nature of the task; the increase in corticosterone levels in this paradigm is within the context of the learning task, whereas usually in other paradigms the critical increase in corticosterone levels occurs before or after the learning situation. A similar finding was reported for a fear-conditioning paradigm, in which higher shock intensities were associated with better acquisition of the task (Cordero and Sandi 1998).

The findings regarding an inverted U-shaped function between corticosterone levels and performance in a spatial learning task are consistent with studies examining the effects of corticosterone administration on synaptic plasticity. At low or high doses of corticosterone, the correlation between plasma corticosterone levels and synaptic plasticity [long term potentiation (LTP) or prime burst potentiation (PBP), the most studied cellular models for learning and memory formation] was negative, whereas peak potentiation was obtained at intermediate plasma corticosterone concentrations (Diamond et al. 1992; Rey et al. 1994; Pavlides et al. 1995).

\section{Summary}

Modification in corticosteroid levels may change our responsiveness to environmental influences, thereby altering our behavioral adaptation to the situation. Under conditions of high stress and anxiety, it is hypothesized that subjects will show impaired attentional processes, for example, problems discriminating between relevant and irrelevant stimuli, and such impairments will 
A

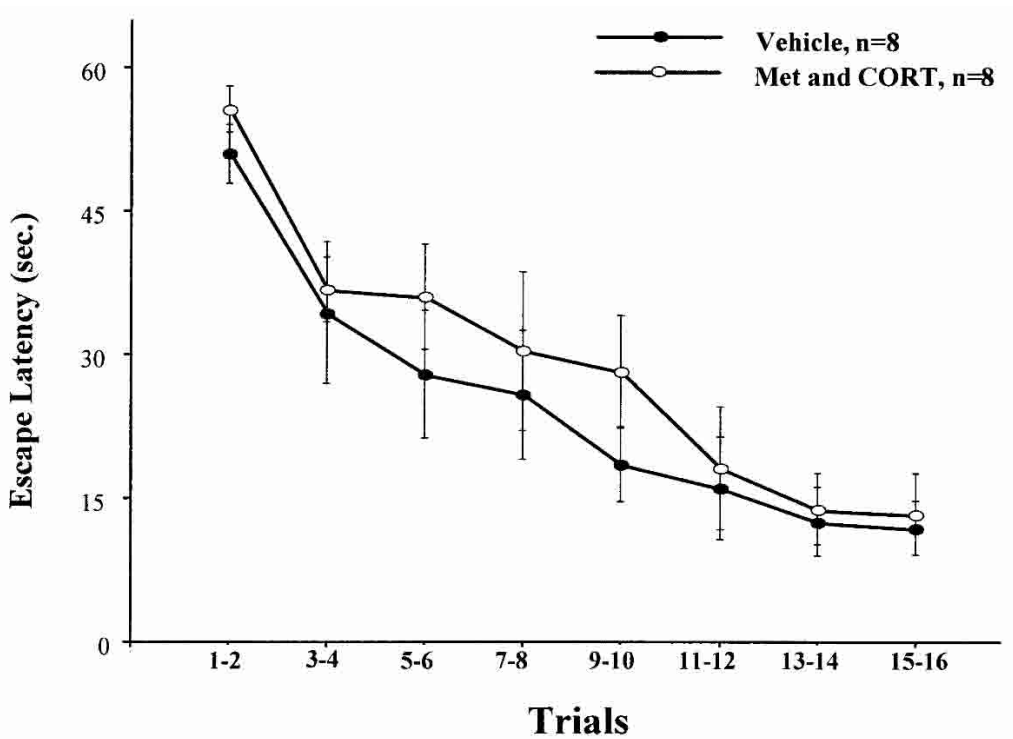

B

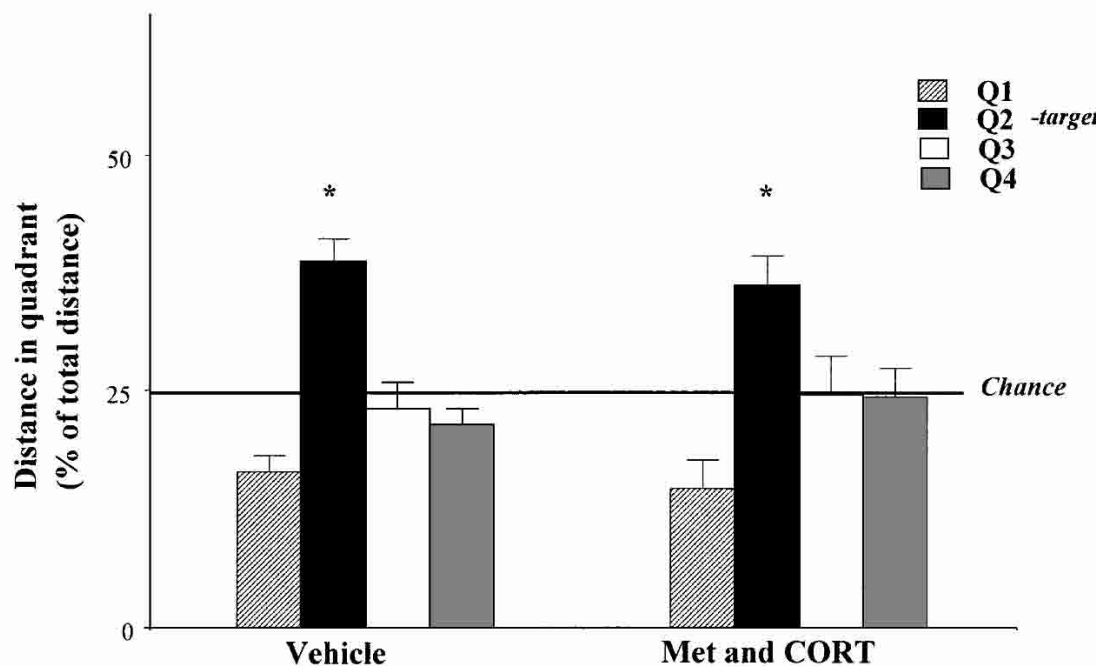

Figure 5 Animals treated with both metyrapone and corticosterone show good performance in cold water. $(A)$ No significant difference in performance (measured as escape latency) was found between the Vehicle group and the Met and CORT group. Thus the effects of metyrapone (Fig. 3) are mainly due to its effect on the glucocorticoid system. $(B)$ In the quadrant test, both the vehicle and the Met and CORT groups showed a significant bias to swim the longest distance within the quadrant in which the platform had been located previously (Q2; Vehicle: ${ }^{*}, P<0.01$, Met and CORT: ${ }^{*}, P<0.05$ ).

easily prevent successful acquisition of useful information (Lupien and McEwen 1997).

It would be of special interest to characterize the negative and facilitative effects of corticosterone on cognition in situations of high arousal and anxiety and under pathological conditions. For example, subjects with social phobia have high stress and anxiety levels, which cause them to overconcentrate on emotional and defensive coping mechanisms and pay insufficient attention to problem-solving coping mechanisms; this, in turn, results in lower levels of performance in a variety of tasks.

This study demonstrated the crucial involvement of corticosterone in determining the strength of learning and memory for the spatial task under different stressful conditions. However, the involvement of other neurobiological systems obviously can- not be ruled out. For example, the involvement of other brain structures such as the prefrontal cortex or the involvement of other neuromodulators and neurotransmitters such as the noradrenergic, the cholinergic, and the glutamatergic systems, should be further examined.

\section{MATERIALS AND METHODS}

\section{Animals}

Adult, male Wistar rats weighing 280 $320 \mathrm{~g}$, from Harlan, were maintained five per cage on a 12-h light/dark cycle with water and laboratory rodent chow ad libitum. Experiments were conducted between 12:00 and 17:00 $\mathrm{h}$.

\section{Drug Administration}

Metyrapone (Met; $25 \mathrm{mg} / \mathrm{kg}, 50 \mathrm{mg} / \mathrm{kg}$, or $75 \mathrm{mg} / \mathrm{kg}$, dissolved in a vehicle containing $40 \%$ polyethylene glycol and $60 \%$ saline, i.p. injection; Aldrich Chemicals) reduces the synthesis of corticosterone by inhibiting the $11 \lambda$ hydroxylation reaction in the adrenal glands. Metyrapone has no effect on baseline corticosterone levels, but it blocks the stress-induced increase in plasma corticosterone (de Quervain et al. 1998).

Corticosterone (CORT; $10 \mathrm{mg} / \mathrm{kg}$ or $25 \mathrm{mg} / \mathrm{kg}$ dissolved in a vehicle containing $15 \%$ sesame oil, $50 \%$ polyethylene glycol, and 35\% saline, i.p. injection; $\mathrm{Al}$ drich Chemicals) is a GR and MR agonist. The CORT doses used are known to induce plasma levels of the steroid comparable with those elicited by substantial stress (Sandi et al. 1997).

Rats were injected with drugs or vehicle as indicated $2 \mathrm{hr}$ before commencing the training.

Control animals were injected with vehicle $(40 \%$ polyethylene glycol and $60 \%$ saline or $15 \%$ sesame oil, $50 \%$ polyethylene glycol and 35\% saline).

\section{Spatial Learning Procedure and the Quadrant Test}

The water maze was a black-painted metal tank (diameter $1.7 \mathrm{~m}$; rim 50 $\mathrm{cm}$ high) containing several extramaze cues (including the door, cabinets, and posters on the walls). The tank was filled with water at cold $\left(19^{\circ} \mathrm{C}\right)$ or warm $\left(25^{\circ} \mathrm{C}\right)$ temperature.

For the spatial training task, a $12 \times 12$-cm escape platform was placed with the top surface $2-3 \mathrm{~cm}$ below the water level at one of four positions in the pool.

Each trial was initiated by placing the animal in one of the three randomly chosen locations near the wall of the tank. Animals were allowed to search for the hidden platform for a maximum of $60 \mathrm{sec}$. The escape latency was measured by a stopwatch. When an animal reached the platform, or at the end of the 60 $\mathrm{sec}$, it was left on the platform, or placed there by the experimenter for $15 \mathrm{sec}$

Because we wanted to examine whether corticosterone is instrumental in the acquisition of the spatial learning task, we used a 1-d massed protocol of training in which the acquisition 
of the task lasts about $1 \mathrm{~h}$ (as opposed to spaced training of a few days).

Rats were trained with inter-trial intervals (iti) of 1 and 4 min, alternately, until they accomplished eight blocks of two trials each. This massed schedule of training took $\sim 1 \mathrm{~h}$ and was found to generate long-term spatial memory (Akirav et al. 2001).

A 60-sec quadrant test (no platform in the maze) was conducted on all of the animals $1 \mathrm{~h}$ following the last behavioral trial by means of a video tracking system.

All behavioral training was performed by an experimenter who was kept blind to the drug treatment; the drug experiments were performed with different groups of animals, and the rats were trained across groups to prevent cyclical variation in corticosterone levels.

\section{Corticosterone Radioimmunoassay}

Animals were injected with vehicle, $50 \mathrm{mg} / \mathrm{kg}$ metyrapone, or 10 $\mathrm{mg} / \mathrm{kg}$ CORT, and after $2 \mathrm{~h}$, swam in cold water (metyrapone group) or warm water (corticosterone group) for one block (two trials, iti $1 \mathrm{~min}$; no escape platform in the maze). Animals were decapitated and trunk blood was collected 20 min following the end of the block. Samples were centrifuged at 3000 r.p.m. for 20 $\min$ at $4^{\circ} \mathrm{C}$. Serum was stored at $-80^{\circ} \mathrm{C}$. Corticosterone was measured using a radioimmunoassay kit (Coat-A-Count, Diagnostic Products Corporation).

\section{Statistical Analysis}

Results are expressed as means \pm SEM. Corticosterone levels were assessed by one-way ANOVA. Spatial performance was assessed by $8 \times 8$ (treatment $\times$ trials) overall mixed ANOVA, ANOVA, and $t$-test. The quadrant test was assessed by $t$-test for difference from chance (25\%). All post-hoc comparisons were made by the least significant difference multiple-comparison test (LSD).

\section{Approval}

The experiments were approved by the institutional Animal Care and Use Committee, and adequate measures were taken to minimize pain or discomfort in accordance with the guidelines laid down by the NIH in the US regarding the care and use of animals for experimental procedures.

\section{ACKNOWLEDGMENTS}

We thank Mira Maroun for her assistance. Supported by a grant from The National Institute for Psychobiology in Israel, number 29-01 to G.R-L.

The publication costs of this article were defrayed in part by payment of page charges. This article must therefore be hereby marked "advertisement" in accordance with 18 USC section 1734 solely to indicate this fact.

\section{REFERENCES}

Akirav, I., Sandi, C., and Richter-Levin, G. 2001. Differential activation of hippocampus and amygdala following spatial learning under stress. Eur. J. Neurosci. 14: 719-725.

Alvarado, M.C. and Rudy, J.W. 1995. Comparison of "configural" discrimination problems: Implications for understanding the role of the hippocampus formation in learning and memory. Psychobiology 23: $178-184$

Anderson, C.R. 1976. Coping behaviors as intervening mechanisms in the inverted U stress-performance relationship. J. Appl. Psychol. 61: 30-34.

Cahill, L., Pham, C.A. and Setlow, B. 2000. Impaired memory consolidation in rats produced with $\beta$-adrenergic blockade. Neurobiol. Learn. Mem. 74: 259-266.

Conrad, C.D., Lupien, S.J., Thanasoulis, L.C., and McEwen, B.S. 1997. The effects of type I and type II corticosteroid receptor agonists on exploratory behavior and spatial memory in the Y-maze. Brain Res. 6: 76-83.

Conrad, C.D., Lupien, S.J., and McEwen, B.S. 1999. Support for a bimodal role for type II adrenal steroid receptors in spatial memory. Neurobiol. Learn. Mem. 72: 39-46.

Cordero, M.I. and Sandi, C. 1998. A role for brain glucocorticoid receptors in contextual fear conditioning: Dependence upon training intensity. Brain Res. 9: 11-17.

de Quervain, D.J., Roozendaal, B., and McGaugh, J.L. 1998. Stress and glucocorticoids impair retrieval of long-term spatial memory. Nature 20: $787-790$.
Diamond, D.M., Bennett, M.C., Fleshner, M., and Rose, G.M. 1992. Inverted-U relationship between the level of peripheral corticosterone and the magnitude of hippocampal primed burst potentiation. Hippocampus 2: 421-430.

Diamond, D.M., Fleshner, M., Ingersoll, N., and Rose, G.M. 1996. Psychological stress impairs spatial working memory: Relevance to electrophysiological studies of hippocampal function. Behav. Neurosci. 110: 661-672.

Diamond, D.M., Park, C.R., Heman, K.L., and Rose, G.M. 1999. Exposing rats to a predator impairs spatial working memory in the radial arm water maze. Hippocampus 9: 542-552.

Easterbrook, J.A. 1959. The effect of emotion on cue utilization and the organization of behavior. Psychol. Rev. 66: 183-201.

Flood, J.F., Vidal, D., Bennett, E.L., Orme, A.E., Vasquez, S., and Jarvik, M.E. 1978. Memory facilitating and anti-amnesic effects of corticosteroids. Pharmacol. Biochem. Behav. 8: 81-87.

Liu, L., Tsuji, M., Takeda, H., Takada, K., and Matsumiya, T. 1999. Adrenocortical suppression blocks the enhancement of memory storage produced by exposure to psychological stress in rats. Brain Res. 6: $134-140$.

Lupien, S.J. and McEwen, B.S. 1997. The acute effects of corticosteroids on cognition: Integration of animal and human model studies. Brain Res. Rev. 24: 1-27.

Mabry, T., Gold, P., and McCarty, R. 1995. Age related changes in plasma catecholamine responses to acute swim stress. Neurobiol. Learn. Mem. 63: 260-268.

McEwen, B.S. and Sapolsky, R.M. 1995. Stress and cognitive function. Curr. Opin. Neurobiol. 5: 205-216.

McEwen, B.S., De Kloet, E.R., and Rostene, W. 1986. Adrenal steroid receptors and actions in the nervous system. Physiol. Rev. 66: $1121-1188$.

Meck, W.H., Church, R.M., and Olton, D.S. 1984. Hippocampus, time and memory. Behav. Neurosci. 98: 3-22.

Morris, R.G., Garrud, P., Rawlins, J.N., and O'Keefe, J. 1982. Place navigation impaired in rats with hippocampal lesions. Nature 24: 681-683.

Moser, E., Moser, M.B., and Andersen, P. 1993. Spatial learning impairment parallels the magnitude of dorsal hippocampal lesions, but is hardly present following ventral lesions. J. Neurosci. 13: $916-925$.

Oitzl, M.S. and de Kloet, E.R. 1992. Selective corticosteroid antagonists modulate specific aspects of spatial orientation learning. Behav. Neurosci. 106: $62-71$.

Oitzl, M.S., Fluttert, M., and de Kloet, E.R. 1994. The effect of corticosterone on reactivity to spatial novelty is mediated by central mineralocorticosteroid receptors. Eur. J. Neurosci. 1: 1072-1079.

Oitzl, M.S., Fluttert, M., Sutanto, W., and de Kloet, E.R. 1998. Continuous blockade of brain glucocorticoid receptors facilitates spatial learning and memory in rats. Eur. J. Neurosci. 10: 3759-3766.

Pavlides, C., Watanabe, Y., Magarinos, A.M., and McEwen, B.S. 1995. Opposing roles of type I and type II adrenal steroid receptors in hippocampal long-term potentiation. Neuroscience 68: 387-394.

Pugh, C.R., Tremblay, D., Fleshner, M., and Rudy, J.W. 1997. A selective role for corticosterone in contextual-fear conditioning. Behav. Neurosci. 111: 503-511.

Reul, J.M. and de Kloet, E.R. 1985. Two receptor systems for corticosterone in rat brain: Microdistribution and differential occupation. Endocrinology 117: 2505-2511.

Rey, M., Carlier, E., Talmi, M., and Soumireu-Mourat, B. 1994. Corticosterone effects on long-term potentiation in mouse hippocampal slices. Neuroendocrinology 60: 36-41.

Sandi, C. and Rose, S.P. 1994a. Corticosterone enhances long-term retention in one-day-old chicks trained in a weak passive avoidance learning paradigm. Brain Res. 30: 106-112.

. 1994b. Corticosteroid receptor antagonists are amnestic for passive avoidance learning in day-old chicks. Eur. J. Neurosci. 1: 1292-1297.

Sandi, C., Loscertales, M., and Guaza, C. 1997. Experience-dependent facilitating effect of corticosterone on spatial memory formation in the water maze. Eur. J. Neurosci. 9: 637-642.

Selden, N.R., Cole, B.J., Everitt, B.J., and Robbins, T.W. 1990. Damage to ceruleo-cortical noradrenergic projections impairs locally cued but enhances spatially cued water maze acquisition. Behav. Brain Res. 18: $29-51$.

Vaher, P.R., Luine, V.N., Gould, E., and McEwen, B.S. 1994. Effects of adrenalectomy on spatial memory performance and dentate gyrus morphology. Brain Res. 5: 71-78.

Vroom, V.H. 1964. Work and motivation. Wiley, New York.

Yau, J.L., Olsson, T., Morris, R.G., Meaney, M.J., and Seckl, J.R. 1995. Glucocorticoids, hippocampal corticosteroid receptor gene expression and antidepressant treatment: Relationship with spatial learning in young and aged rats. Neuroscience 66: 571-581.

Received March 24, 2003; accepted in revised form November 24, 2003. 


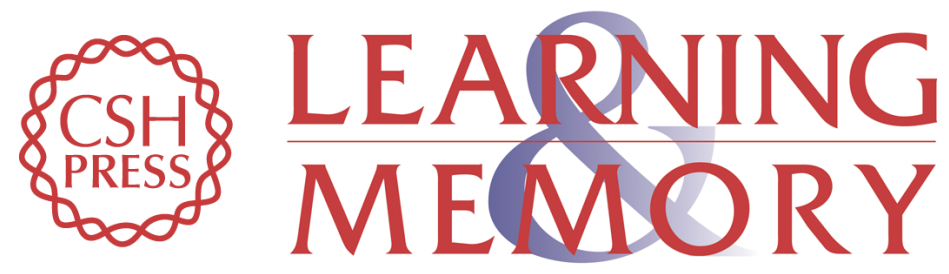

\section{A Facilitative Role for Corticosterone in the Acquisition of a Spatial Task Under Moderate Stress}

Irit Akirav, Maya Kozenicky, Dadi Tal, et al.

Learn. Mem. 2004, 11:

Access the most recent version at doi:10.1101//m.61704

\section{License}

Email Alerting

Receive free email alerts when new articles cite this article - sign up in the box at the top

Service right corner of the article or click here. 